\title{
Economic Growth and Multidimency Poverty Reduction in Vietnam
}

\author{
Dr. Nguyen Minh Tri ${ }^{1}$, Dr. Luu Thanh Tam ${ }^{2}$ \\ ${ }^{1,2}$ Ho Chi Minh City University of Technology (HUTECH), Ho Chi Minh City, Vietnam \\ E-mail: nm.tri@hutech.edu.vn ${ }^{1}$; lttam@hutech.edu.vn² \\ Article History: Received: 10 November 2020; Revised 12 January 2021; Accepted: 27 January 2021; \\ Published online: 5 April 2021
}

\begin{abstract}
Abstrct
Economic growth is a necessary condition, but not a sufficient condition to multidimency reduce poverty. In contrast, reducing poverty promotes economic growth, but it can also hinder economic growth. In recent years, Vietnam has achieved great achievements in the implementation of economic growth, which has contributed to reducing poverty and is highly appreciated by the international community. However, there are still certain limitations that require the Government of Vietnam to take concrete and appropriate measures to ensure both economic growth and sustainable poverty reduction.
\end{abstract}

Keywords: economic growth, multidimency poverty reduction, Vietnam.

\section{Introduction}

In the process of human development, economic growth with poverty reduction is one of the basic problems of every age, because it is posed with the existence of people, associated with dreams and aspirations for a happy life of humans. Therefore, the determination of the true value of development, and at the same time, gathering, using and promoting effectively resources to resolve harmoniously between economic growth and poverty reduction become urgent needs.

Over the years, Vietnam has achieved important achievements in realizing economic growth and poverty reduction. However, besides the achieved achievements, the implementation of economic growth with poverty reduction remains as the division of rich and poor, high unemployment, unsustainable poverty reduction, income inequality, increasing disparities in living standards... In this context, the continuation of economic growth research and poverty reduction in Vietnam in the process of international integration is one of the necessary works, both theoretically and practically. This is also the main content of this article.

\section{Literature Review}

It is common knowledge that the poor are a society that needs help so that they can get out of poverty. Therefore, the measure of poverty must be accurate to describe poverty. Thisis because it will provide a clear understanding related to poverty so that the policies that will be formed are believed to be able to solve the problems of poverty faced (Alkire\&Foster, 2011). In 1997, the Human Development Report and the 2000/1 World Development Report 
stated that poverty was a multidimensional phenomenon. While the Millennium Declaration and the MDGs began discussing the issue of poverty in multidimensional since 2000.

One of the multidimensional poverty measurement methods is to use the Alkire and Foster Method (AF Method). Poverty measurement using this AF Method contains the poverty dimension, the dimensional separating line to determine who is poor in that dimension, and the poverty separation line is used to determine who is suffering enough to be classified as multidimensionally poor. This method is believed to be able to identify who is poor and, in turn, will be able to solve the problem of poverty faced (Alkire\&Foster, 2011). Santos and Ura have applied the AF Method in their study on Bhutan. The study was conducted in rural and urban areas. Five dimensions have been used, namely income, education, number of available rooms, access to electricity, and drinking water. Two additional dimensions are only analyzed in rural areas, namely, access to roads and land ownership (Santos \& Ura, 2008).

Mussard and Alperin introduced a new methodology to measure the imbalance in multidimensional poverty between population groups and dimensions. The study was conducted in Argentina in 1998 on 28,511 households. The variables studied were: type of occupation and location of household residence, type of household, household size, toilet characteristics, flowing characteristic, total household income, level of education, stable employment, social contribution, and the ratio of the number of households to total income. The findings of the study indicate that the main dimensions that contribute to poverty imbalance are toilet characteristics, household size, stable employment, and flowing characteristics (Mussard \& Alperin, 2008).

Notten did a study in the Republic of Congo. This study attempts to identify the poverty patterns of the Congolese people and how they differ between women, men, and children (individual poverty). The study was conducted in 2005. The information collected included household expenses, living conditions, and individual characteristics. The eight indicators of well-being studied are money or income (household level), education (individual level), nutrition (household level), health (individual level), employment (individual level), water and sanitation (household level), home/residence (household level) and integration (relationship) (household level). This Notten study found that the poorest dimensions of poverty were housing and water \& sanitation, followed by poverty in terms of finance or income (Notten, 2008).

In addition to foreign documents, related to poor fields, there are also domestic documents such as: The author Luong Thi Hong presents the Party's new points on hunger eradication and poverty alleviation and basic concepts and formulas for the implementation of hunger eradication and poverty reduction in Vietnam. Looking back after 30 country renewal. The author said that, the innovation company in Vietnam has made great achievements which means history. In particular, Vietnam and the international community recognized as one of the 18 countries with the best achievements in hunger eradication and poverty reduction in the world and one of the few countries that achieved 5/8 millennium development goals century. With the right policy, the consensus and support of all walks of life and social strata, the work of hunger eradication and poverty reduction in Vietnam has been beneficial (Luong, 2016). 
Dinh Cong Tuan have analyzed an overview of Europe's poverty reduction policies as well as clarified the needs and challenges in policy reform. poverty reduction in Europe, at the same time, pointed out the successes, limitations, experiences in the implementation of poverty reduction the German "social market" model; social security system model of "democratic society" of Sweden. Since then, providing many scientific arguments for the formulation and implementation of poverty reduction policies consistent with the current conditions of Vietnam (Dinh, 2008).

"Economic growth with poverty reduction in Vietnam today" by Vu Thi Vinh, analysis of theoretical and practical problems of economic growth with poverty reduction; assessing the implementation of linking the economic growth target with poverty reduction in Vietnam (the period 1986 - 2012), thereby proposing the main solution to combine economic growth with poverty reduction. The work affirms "Economic growth with poverty reduction has a close relationship with each other. High economic growth is a key factor in poverty reduction. Poverty reduction is a factor that ensures sustainable economic growth" (Vu, 2014: 229).

In general, publications and concepts of a number of scholars are mentioned in all emphasized that the implementation of multidimensional poverty reduction is the measure to create conditions for all people to integrate into society, ensure social equity and progress in the development process.

\section{Research Methods}

Economic growth is an increase in gross national product or an increase in gross national product per capita over a given period (usually a year). The connotation of growth is expressed in scale and speed. The scale of growth reflects the increase more or less, while the growth rate is used with relative comparative meaning and reflects the rapid or slow increase of the periods. Economic growth is often expressed as value, measured by value indicators such as: Gross domestic product (GDP); Gross national income (GNP); Per capita income (GDP/person/year)... If the scale and growth rate of the indicators reflect a high total income and per capita income, it is a positive sign of quantity of economic growth.

From the World Bank's point of view: Poverty is a shortage in many ways. Limited income or lack of opportunities to generate income, assets to ensure consumption in times of difficulty and vulnerability to adverse mutations, inability to communicate needs and difficulties to those people who are capable of dealing, feeling insulted, not being respected by others... that's the aspect of poverty. At the conference on hunger eradication and poverty reduction in Asia - Pacific region organized by ESCAP in Bangkok - Thailand in September 1993, the Asia - Pacific Economic and Social Committee introduced the conception: Poverty is the situation in which a population segment does not enjoy and satisfies basic human needs, but this need has been inherited by society depending on the level of socio-economic development, habits and customs of locality. From this it can be understood: Poverty reduction is to make a part of the poor population raise their living standards and gradually get out of poverty. In other words, poverty reduction is the process of moving a part of the poor population to a higher standard of living.

Economic growth with poverty reduction is considered for the sake of human development, the subject of the development process, in which economic growth is a condition for poverty 
reduction and poverty reduction is a measure of social progress; poverty reduction is a driving force for high and sustainable economic growth; poverty reduction is an indicator of economic growth; Implementing appropriate poverty reduction will become a driving force for high and sustainable economic growth, showing:

Firstly, it is necessary to affirm that economic growth is a necessary condition for poverty reduction. It must take economic growth, especially high, stable and long-term economic growth, for the State to have the physical strength to implement poverty reduction programs. In fact, in many countries, the high economic growth rate has had a positive impact on the poverty rate. For example, in the 1990s, East Asian countries experienced high growth rates (6.4\%) and poverty reduction rates of $6.8 \%$; while in South Asian countries, figures are 3.3\% and $2.4 \%$, respectively. Without economic growth, or slow economic growth, the State will not have many resources to implement poverty reduction policies.

However, economic growth is only a necessary condition, not a sufficient condition to reduce poverty. In fact, some countries have higher economic growth and per capita income, but the results of poverty reduction are less effective. In contrast, there are lower income per capita countries, but poverty reduction is better. For example, in 2018, Mexico's per capita income was $\$ 17,628$ (calculated according to PPP 2011), but their national poverty rate reached $43.6 \%$, the international poverty rate was $2.5 \%$; the corresponding figures of Brazil are $\$$ 14,068, 26.5\% and 4.8\%; of East Timor is \$ 7,527, 41.8\% and 30.7\%. Meanwhile, Vietnam's per capita income reached only $\$ 6,220$, but the national poverty rate is only $9.8 \%$ and the international poverty rate is $2.0 \%$, the corresponding figures of China. These are $\$ 16,127$, $3.1 \%$ and $0.7 \%$ (UNDP, 2020).

Thus, in order to promote poverty reduction, in addition to what is needed for economic growth, there must be sufficient conditions for the role of the State, expressed in the following aspects:

(i) Select an economic growth model. If the Government chooses a model of rapid economic growth, taking place in sectors and fields that require high level of technology and human resources, it will not attract the poor to participate. Therefore they do not benefit directly from the results of growth. Or the Government accelerated industrialization, modernization, and urbanization, leading to the situation of land acquisition of farmers' land, while not guaranteeing job change for them, pushing them into unemployment, which increases poverty.

(ii) Distribute the results of growth. If the Government concentrates too much resources on the goal of economic growth, then it will reduce the resources for the goal of poverty reduction and possibly increase the poverty situation; or if the Government only concentrates its resources in key areas and key sectors to promote rapid economic growth, without paying adequate attention to disadvantaged and poor areas, it will lead to development of the imbalance, the richer region is richer, the poorer the poor area, the rich-poor gap will become more severe.

Secondly, poverty reduction promotes economic growth, but can also hinder economic growth. Poverty reduction has an impact on economic growth again. It can promote or hinder economic growth. 
(i) Poverty reduction promotes economic growth. Policies to lend money to the poor at preferential interest rates, provide vocational training for the poor, develop infrastructure for poor areas, create opportunities for the poor to participate in economic activities... contributing increase production capacity (increase investment capital, increase human resources, increase infrastructure for production development...), increase employment opportunities for the poor and poor areas, thus promoting economic growth. Poverty reduction also helps to stabilize society, facilitating rapid and sustainable economic growth.

(ii) However, poor implementation of poverty can hinder economic growth. If the Government attaches too much importance to measures to support the poor and poor regions that do not go along with raising production capacity for the poor and poor regions, raising the self-esteem, self-reliance and the will to escape poverty... may increase the dependence of the poor on the Government, losing the driving force for economic growth.

\section{Results and discussion}

\section{The reality of economic growth and multidimency poverty reduction in Vietnam}

Positive impact of economic growth on multidimency poverty reduction

First, economic growth promotes an increase in per capita income and investment capital for poverty reduction. Implementing a comprehensive renovation path, especially in the economic field, since 1986 up to now, Vietnam has always achieved positive economic growth, with an average of 1991 - 2010 of 7.03\%/year and the period 2011 - 2019 about $6.08 \% / y e a r$. Besides, the population growth rate under control has had a positive impact, boosting Vietnam's per capita income constantly, from 206.1 thousand VND/person in 1995 to 3,876 thousand VND/person in 2018 (current price). Economic growth facilitates the increase of investment capital for poverty reduction: economic growth continues at a high rate, so the state budget revenue is also increasing. As a result, the investment capital for poverty reduction increased rapidly from VND 10 trillion in the 1998-2000 period to VND 16,245 billion in the 2001-2005 period, and VND 43,488 billion in the 2006 - 2010 period. In the 2011-2015 period, the economy faced many difficulties, so the capital source for poverty reduction decreased compared to the previous period, but still reached VND 32,982 billion and increased to VND 46,161 billion in the 2016-2020 period (Government Vietnam, 2020). Second, economic growth is constantly accompanied by a reduction in the proportion of poor households. With fast and stable economic growth, material resources have been created to reduce poverty for all Vietnamese people. Accordingly, the rate of poor households decreased rapidly from $28.9 \%$ in 2002 to $11.1 \%$ in 2012 and $5.8 \%$ in 2016 . The proportion of multidimensional poor households also decreased rapidly from $9.2 \%$ in 2016 , to $7.8 \%$ in 2017 , $6.8 \%$ in 2018 and 2019 is estimated to be about $3.73-4.23 \%$.

Third, economic growth is more beneficial to the poor. By comparing the growth rate of per capita income and the rate of poverty reduction in the period of $2003-2018$, it can be seen that in Vietnam, the impact of economic growth is more beneficial to the poor than with other population groups.

Table 2 shows that, on average during the period of 2002-2018, the rate of poverty reduction in Vietnam was $10.1 \%$ / year, greater than the growth rate of per capita income in the same period of 7, 8 years. This means that Vietnam's economic growth during this period "for the poor" is more beneficial to the poor. In other words, the consensus effect of economic growth 
on poverty reduction is strong and rapid poverty reduction. However, in 2009 and 2010 alone, the poverty rate did not decrease, but increased, meaning that economic growth in these two years was more beneficial to the rich than to the poor.

\section{Restricting the effects of economic growth on multidimency poverty reduction}

First, the positive impact of economic growth on poverty reduction is uneven among population groups and ethnic groups. Vietnam's economic growth in recent decades has had a positive impact on poverty reduction in general. However, this effect is not equal among the population groups, the rich groups benefit more from the fruits of economic growth than the poor. This is reflected in the growing income gap between the richest $20 \%$ of the population and the poorest $20 \%$ of the population, and the proportion of income of the poorest $40 \%$ of the total population is getting smaller and smaller.

During 1995 - 1999, the income gap between these two groups was lower than 8 times (ie inequality in low income distribution). In the period of 2002-2008, the gap was in the range of 8.1 - 8.9 times (i.e., is below the moderate inequality in income distribution). From 2010 to 2016, the gap increased to 9.2 - 9.8 times (ie, near upper moderate inequality in income distribution). In 2018, this gap increased by 10 times, which is a high level of inequality. Considering the World Bank's "standard 40", in the period 2002-2006, the income share of the poorest $40 \%$ of the total income accounted for $>17 \%$ (corresponding to low inequality), since in 2008, the ratio was between $12 \%-17 \%$ (i.e., moderate inequality) (Thao, 2020). This shows that the gap between rich and poor increased, the poor benefited less as a result of economic growth than the rich.

The positive impact of economic growth on poverty reduction is uneven among ethnic groups. In general, the positive impact of economic growth on poverty reduction for ethnic minorities is lower than for the Kinh people. In 2017, the proportion of poor ethnic minority households accounted for $52.66 \%$ of the total poor households nationwide and accounted for $27.55 \%$ of the total ethnic minority households. Some poor districts of 30 a have a poverty rate of over $60 \%$. In 2018, poor ethnic minority households accounted for $62.51 \%$ compared to the total poor households in 51 ethnic minority and mountainous provinces (Nguyet Ha, 2019). There are 10 ethnic minorities with high poverty rate from $45.7 \%$ to $83.9 \%$, namely: La Hu (83.9\%), Mang (79.5\%), Chut (75.3\%), O Du (66.3\%), La Ha (47.7\%), Co (65.7\%), Kho Mu (59.4\%), Xinh Mun (52.4\%), Khang (46, 1\%), Mong (45.7\%) (Thao, 2020).

Second, the ability to access production factors of the poor is limited, many poor rely on the support of the State, reducing the motivation for economic growth. According to the 2016 Living Standards Survey, the proportion of poor households receiving credit support in recent years has been declining. In 2010, this ratio was 9.9\%, in 2012 it decreased to $9.1 \%$, in 2014 it was only $3.4 \%$ and in 2016 it was $1.0 \%$. The proportion of poor households supported with residential land and productive land has also decreased, from $1.2 \%$ (2010) to $0.8 \%$ in 2012, $0.5 \%$ (2014) and $0.3 \%$ (2016). The rate of ethnic minority households allocated land and forests is very low, accounting for $11.5 \%$ of ethnic minority households; In 2018, there were 303,578 households lacking productive land; 96,256 households lack capital and need to borrow capital to develop production (Thao, 2020).

In addition, many poor households rely on the support of the State, not consciously rising out of poverty is also an obstacle to economic growth. This situation occurs in many communes 
of 135 where the poverty rate is over $60 \%$. In many $\mathrm{La} \mathrm{Hu}$ villages, people mainly cultivate on upland fields and go to the forest to gather for the seasons. This is also the community that always maintains the poverty rate of more than $80 \%$ in Lai Chau province. Over the years, food, shelter, seedlings and livestock have been provided by the State, but many households have not been able to escape poverty (News Department, 2019).

Third, poverty reduction is not sustainable, and the risk of falling back into poverty is high. Despite impressive achievements, poverty reduction in Vietnam has not been truly sustainable. For example, in the two years of 2016 - 2017, the rate of households falling back into poverty accounted for an average of 5.17\%/year of the total number of households escaping from poverty, particularly in the Northwest mountainous region, the rate of people falling back to poverty reached $26.86 \%$ (period about $12 \%$ per year in advance). Notably, the proportion of poor households arising is relatively large, equal to $22.98 \%$ of the total households escaping from poverty. In 2017, a high proportion of newly arising poor households (compared to households escaping from poverty) focused on ethnic minority and mountainous areas such as: the Northeast mountainous region (24.67\%); Northwestern mountainous region (39.21\%); Central Highlands (31.74\%). Some provinces have a very high rate of arising new poor households every year, such as: Ha Giang (28.25\%); Cao Bang (25.44\%); Bac Kan (59\%); Son La (52.31\%); Dien Bien (41.5\%); Dak Nong (44\%); Kon Tum (41\%) (Cao, P, 2019). By March 2018, although 8/64 districts 30a escaped from poverty; 14/30 districts enjoyed the 30a mechanism to escape the difficult situation but added 29 districts to the list of poor districts for the period of 2018-2020. In particular, 12 provinces have seen a significant increase in the rate of falling back into poverty, increasing by $0.03 \%$ or more, including some provinces with favorable socio-economic development conditions such as Vinh Phuc, Khanh Hoa and Kien Giang; the number of households falling back into poverty will be about $1 / 20$ households escaping from poverty; the number of newly arising poor households is about one fourth of the households escaping from poverty; Many provinces in areas affected by natural disasters and severe floods have a very high rate of generating new poor households every year (H. Vu, 2018).

\section{A number of solution to better of economic growth and multidimency poverty reduction in Vietnam}

The above analysis shows that, in order to both promote economic growth and sustainably reduce poverty in Vietnam, in the coming time, the Government should focus on the following solutions:

Firstly, to combine the economic growth model with width and depth, focusing on depth. This orientation not only ensures an increase in labor productivity, promotes sustainable economic growth, creates a solid foundation for increasing per capita income, increases capital for poverty reduction, but also creates opportunities for the poor and poor regions participate in the growth process and benefit directly from the economic growth process.

In order to do so, the Government needs to maintain a stable macroeconomic environment, promote restructuring of the economy associated with innovating an important and intensive economic growth model; promote the development of agriculture, rural, deep-lying, remote, poor and ethnic minority areas along the direction of diversifying agricultural production, developing rural economy, building new countryside, creating every opportunity associations 
for farmers, the poor and ethnic minorities to directly participate in economic activities; At the same time, encourage the development of private enterprises, especially those that provide input, output, processing and consumption of agricultural products, and promote the development of rural economy, remote areas, poor areas.

Secondly, improve the policy for distributing the fruits of economic growth to human-related fields. This solution aims to use the fruits of economic growth to improve aspects related to human and social development. The process of economic growth must be controlled regularly and strictly by social development indicators, in which the focus is on hunger eradication, poverty reduction, social justice, job creation, inter-sectoral targets related to the comprehensive development of people (such as education, health, physical training and sports, culture and art). At the same time, the economic growth policies associated with creating conditions are increasingly fair for everyone about development opportunities. This is related to the need to implement policies that enable everyone to participate in the implementation of economic growth; implement policies to make full use of and ensure everyone has the opportunity to participate in economic processes to create growth. The results of economic growth are always associated with improving the living standards for the people, through the policy of income distribution and redistribution. The human-growth model requires the effective use of two methods of income distribution: income distribution by function, that is, each person's income is determined on the basis of the contribution of quantity and the quality of the resources they contribute to generating income for the economy; Income redistribution, in the form of direct (tax, subsidy) and indirect (through price policy access to public services) to contribute to the regulation of income among different strata of society.

Thirdly, increase production capacity for poor and poor areas. Increasing production capacity for the poor, poor areas are the root to ensure sustainable poverty reduction. For this purpose, the Government needs to grasp the importance of "giving fishing rods more". Specifically, it is necessary to: (i) Build synchronous socio-economic infrastructure for poor areas connecting with developed regions, in order to create a foundation to promote production development in poor areas; (ii) Supporting education, training, improving people's literacy and professional and technical qualifications for the poor, so that they have the opportunity to find jobs, participate in the process of economic growth and benefit directly from this process; (iii) Support productive resources for the poor and poor areas, especially support for capital, production techniques and product consumption, as these are weaknesses that the poor cannot overcome on their own.

Fourthly, fundamentally change the methods of poverty reduction, raise the sense of selfreliance, self-reliance, and proactively rise out of poverty. Poverty reduction cannot be successfully accomplished without the personal efforts of poor households, the poor and the poor. To this end, the Government needs to: (i) Reduce the policy of free support, increase the conditional assistance policy attached to beneficiaries, areas and beneficiary duration to increase access to policies for the poor; (ii) Promulgate groundbreaking policies to encourage the active, proactive participation and promotion of internal resources of the poor, (iii) Enhancing communication, changing perceptions of poor households, eliminating ideas rely on and rely on the support of the State, especially to bring the poor from the "passive" 
position to "proactively escape poverty"; (iv) Directing provinces and cities to formulate detailed plans of poverty reduction programs and policies according to specific roadmaps with practical solutions, close to the assistance needs of the poor under specific conditions of provinces, cities, avoiding burning phase; review and classify poor and near-poor households objectively and accurately to take appropriate support measures.

\section{Conclusion}

Over the past years, Vietnam's economic growth has contributed to reducing unemployment, bridging the gap between the richest and poorest quintile, improving material and cultural life, and status of the country. We are constantly improving in the international arena. However, the negative side of the market economy and international integration have negatively impacted on the lives of workers, such as unemployment, rich and poor division, income inequality ... Therefore, promoting moreover, between economic growth and poverty reduction in Vietnam now has great theoretical and practical implications, which need to be properly understood, implemented effectively, in order to realize the goal of "wealthy people, strong country, justice and civilized society".

\section{References}

1. Alkire, S \& Foster, J. (2011). Understanding and Misunderstanding of Multidimensional Poverty Measurement. OPHI Working Paper No. 43.University of Oxford.

2. Cao, P. (2019). Poverty reduction results are not really sustainable. Available at: https://giaoducthoidai.vn/ket-qua-giam-ngheo-chua-thuc-su-ben-vung-3822648.html

3. Dinh, C. T. (2008), The EU's social security system and lessons for Vietnam. Hanoi: Social Science Publishing House.

4. Hoang, V. (2018). "Unsustainable poverty reduction". Available at: http://daidoanket.vn/quochoi/giam-ngheo-chua-ben-vung-tintuc415990

5. General Statistics Office. (2019). Vietnam Statistical Yearbook 2018. Hanoi: Publisher Statistics.

6. Lan, A. (2018). 32 years of renovation, Vietnam ranked in the Top 50 of world economies. Available at: http://www.brandsvietnam.com/17031-32-nam-doi-moi-Viet-Nam-lot-Top-50nen-kinh-te-the-gioi.

7. Mussard, S., \& Alperin, M. N. P (2008). Inequalities in multidimensional poverty: evidence from Argentina. Applied Economics Letters, 15: 759-765.

8. Ministry of Planning and Investment. (2019). Report "Socio-economic situation in 2018, expected socio-economic development plan for 2019".

9. Nguyet, H. (2019). "Will promulgate a Resolution on sustainable poverty reduction in ethnic minority and mountainous areas". Available at: http://baobaohiemxahoi.vn/vi/tin-chi-tiet-seban-hanh-nghi-quyet-ve-giam-ngheo-ben-vung-khu-vuc-dtts-mien-nui-e40ec0fc.aspx

10. Notten, G. (2008). Multidimensional Poverty in the Republic of Congo: Being Poor Simultaneously in Many Ways. BWPI Working Paper 65. Brooks World Poverty Institute. ISBN: 978-1-906518-64-6.

11. News Department. 2019. "How to reduce poverty sustainably". Available at: https://vtv.vn/trong-nuoc/giam-ngheo-the-nao-de-ben-vung-20190915202849366.htm

12. Luong, T. H. (2016), "Looking back 30 years of implementing hunger eradication, poverty reduction, improving people's lives (1986 - 2016)", Party History Magazine, (7), p.29- 34) 
13. Santos, M. E., \& Ura, K. (2008). Multidimensional Poverty in Bhutan: Estimates and Policy Implications. OPHI Working Paper no. 14.

14. Simon, K. (1966). Modern Economic Growth: Rate, Structure and Spread. New Haven, Yale University Press.

15. Thao, N. (2020). "The results of poverty reduction in ethnic minority and mountainous areas are not really sustainable". Available at: https://www.qdnd.vn/chinh-tri/tin-tuc-su-kien/ketqua-giam-ngheo-vung-dan-toc-thieu-so-mien-nui-chua-thuc-su-ben-vung-590767

16. United Nations Development Programme. (1995). Human development report 1995. Oxford University Press.

17. UNDP. (2020). Human Development Report 2019 "Inequality in human development in the 21 st century: Not only in terms of income, average and current", Summary of data from tables 1, p.300, 301, 302 and tables 6, p.320-321,

18. Vietnamese Government. (2020). Comprehensive report from National Target Programs on Poverty Reduction. Vietnam.

19. $\mathrm{Vu}$ Thi Vinh. (2014), Economic growth with poverty reduction in Vietnam today. Hanoi: National Politics - Truth. 